Gumarov I.A., Yakubova S.M.

\title{
ON INTERNATIONAL COOPERATION IN PROVIDING LEGAL ASSISTANCE IN INVESTIGATING CRIMINAL CASES IN THE FORM OF INQUIRY
}

\begin{abstract}
В уголовном процессе при совершении преступлений иностранными гражданами, подданными иностранных государств или лицами без гражданства, а также гражданами Российской Федерации, оказавшимися впоследствии за пределами страны гражданства, в ходе расследования возникает необходимость в производстве на территории иностранного государства следственных и иных процессуальных действий. В статье освещаются проблемы организации оказания правовой помощи при производстве расследования по уголовным делам в форме дознания, подвергнуты анализу типичные ошибки, допускаемые дознавателями при подготовке поручений (запросов) об оказании правой помощи.
\end{abstract}

Ключевые слова: правовая помощь, предварительное расследование, дознание, уголовное дело, запрос, поручение.

In criminal proceedings when crimes are committed by foreign citizens, nationals of foreign states or stateless persons, as well as citizens of the Russian Federation who subsequently find themselves outside the country of citizenship, during the investigation it becomes necessary to conduct investigative and other procedural actions on the territory of a foreign state. The article highlights the problems of organizing the provision of legal assistance during the investigation of criminal cases in the form of inquiry, analyzes the typical mistakes made by interrogators when preparing orders (requests) for providing legal assistance.

Keywords: legal assistance, preliminary investigation, inquiry, criminal case, request, order.

Упрощение порядка выезда из Российской Федерации и въезда в страну граждан России, иностранных граждан и лиц без гражданства [9] оказывают как позитивное, так и негативное влияние на миграционные процессы, воздействуя, в том числе и на сращивание преступных сообществ. Сама по себе глобализация, являясь важным фактором развития цивилизации, тем не менее, способствует транснационализации преступной деятельности. Решение данной проблемы требует объединения и координации усилий мирового сообщества и предполагает интенсивное развитие международного сотрудничества в сфере уголовного судопроизводства [6]. О необходимости такого взаимодействия свидетельствует и статистические данные, согласно которым ежегодно иностранными гражданами и лицами без гражданства на территории Российской Федерации совершается порядка 39000 преступлений. Несмотря на снижение показателей зарегистрированных преступлений в общей массе, не снижается их удельный вес от числа расследованных и составляет 3,5\% [11].

Так, в 2016 г. иностранными гражданами и лицами без гражданства совершено 43933 преступления, удельный вес которых от числа расследованных уголовных дел составляет 3,7\%. Из них гражданами 
государств-участников Содружества Независимых Государств (далее - СНГ) совершено 38501 преступление (или 3,2\% от количества расследованных уголовных дел);

В 2017 г. - 41047 преступлений (или 3,7\% от количества расследованных дел), гражданами государств-участников СНГ - 36233 (или 3,2\% от количества расследованных дел);

в 2018 г. - 38598 преступлений (или 3,5\%), из которых гражданами государств-участников СНГ - 34323 (или $3,2 \%)$;

в 2019 г. - 34917 преступлений (или 3,3\%). Из них гражданами государствучастников СНГ - 31010 (или 2,9\%);

и за 10 месяцев 2020 г. - 29338 (или $3,4 \%)$, из которых гражданами государств-участников СНГ - 26335 (или 3\%) [11].

Поскольку Российская Федерация является суверенным субъектом международных правоотношений, реализуемых на паритетных началах [7, с. 79], в законодательстве страны нашли отражение всемирные тенденции развития межгосударственного сотрудничества в сфере борьбы с преступностью. Международное сотрудничество в уголовном судопроизводстве деятельность компетентных органов государств по оказанию и получению правовой помощи по уголовному делу и принятию иных мер, направленных для его разрешения по существу [10]. В соответствии с положениями основного закона страны общепризнанные принципы и нормы международного права являются составной частью ее правовой системы [5]

Международное сотрудничество по оказанию правовой помощи по уголовным делам предполагает систематические коммуникации между государственными органами различных государств и должностными лицами в борьбе с преступностью. Российская Федерация взаимодействует с иностранными государствами на основе взаимного соблюдения норм, закрепленных в международных договорах, международных соглашениях

Несмотря на то, что дознание производится по уголовным делам о преступлениях, которые обладают меньшей общественной опасностью по сравнению с относящимися к подследственности органов предварительного следствия, для этой формы также характерно расследование уголовных дел о преступлениях, совершенных иностранными гражданами, в связи, с чем возникает необходимость в производстве следственных и иных процессуальных действий на территории иностранных государств в рамках оказания правовой помощи.

Поскольку для исполнения поручения (запроса) об оказания правовой помощи, направленного в установленном порядке, требуются более длительные сроки производства дознания, законодатель предусмотрел возможность продления срока расследования прокурором субъекта Российской Федерации до 12 месяцев (ч. 5 ст. 223 УПК РФ).

В рамках международного сотрудничества оказывается правовая помощь в определенных видах.

Виды правовой помощи по уголовным делам определены международными договорами Российской Федерации и национальным законодательством.

Европейская конвенция о взаимной правовой помощи по уголовным делам 1959 года выделяет следующие виды правовой помощи: 1) выполнение поручений по уголовным делам в целях получения показаний или передачи вещественных доказательств, материалов или документов; в отношении розыска или наложения ареста на имущество при соблюдении одного или нескольких из следующих условий: а) преступление, с которым связано поручение, наказуемо как по закону запрашивающей Стороны, так и по закону запрашиваемой Стороны; б) преступление, с которым связано поручение, является в запрашиваемой стране преступлением, в связи с которым предусматривается выдача; в) исполнение поручения не противоречит законодательству запрашиваемой Стороны; 2) вручение повесток и судебных постановлений для явки свидетелей, экспертов и обвиняемых; 3) передача материалов из судебных материалов и информации о них [1].

Европейской конвенцией о выдаче, имеющей приоритет перед любыми двусторонними договорами, предусмотрен такой вид правовой помощи, как выдача лиц, в отношении которых осуществляется расследование в связи с совершением им преступления (преступлений) либо разыскиваются компетентными органами для приведения в исполнение приговора или задержания для избрания меры пресечения в виде заключения под стражу [2].

Отметим, что обязательство о выдаче подлежит выполнению за совершение преступлений, по которым по законодательству как запрашивающей Стороны, так и запрашиваемой Стороны предусмотрено наказание в виде лишения свободы или в соответствии с постановлением об аресте не менее одного года либо более строгое наказание. При этом ука- 
занной Конвенцией предусмотрено право Договаривающихся Сторон за совершение некоторых преступлений не выдавать таких лиц [2].

В Конвенции о правовой помощи и правовых отношениях по гражданским, семейным и уголовным делам (в редакции протокола от 28.03.1997; заключена в г. Минске) предусмотрены следующие виды правовой помощи по уголовным делам (раздел I, части I и II): 1) выполнение поручений о составлении, пересылке и вручении документов, проведении осмотров, обысков, проведении экспертизы, изъятия и передачи вещественных доказательств, допросах сторон, третьих лиц, подозреваемых, обвиняемых, потерпевших, свидетелей, экспертов; 2) вызов свидетелей, потерпевших, гражданских истцов, гражданских ответчиков, их представителей, а также экспертов; 3) розыск лиц для уголовного преследования, их выдача для привлечения к уголовной ответственности или приведения приговора в исполнение; 4) осуществление уголовного преследования; 5) сведения о действующем или действовавшем на их территориях внутреннем законодательстве и о практике его применения; 6) передача на время лица, находящегося под стражей или отбывающего наказание в виде лишения свободы; 7) исполнение приговоров в части гражданского иска [4].

В двусторонних договорах, заключенных Российской Федерацией, содержатся аналогичные приведенным выше конвенциям виды правовой помощи, с некоторыми изъятиями при сношениях между государствами. Так, Договором между Российской Федерацией и Азербайджанской Республикой о правовой помощи и правовых отношениях по гражданским, семейным и уголовным делам не указано на допустимость производства обыска [3].

Следует отметить, что в действующем УПК РФ предусмотрены следующие формы международного сотрудничества:

- оказание правовой помощи (гл. 55 УПК РФ);

- выдача лица для уголовного преследования или исполнения приговора (глава 54 УПК РФ);

- передача лица, осужденного к лишению свободы, для отбывания наказания в государстве, гражданином которого оно является (гл. 55 УПК РФ);

- производство по рассмотрению и разрешению вопросов, связанных с признанием и принудительным исполнением приговора, постановления суда иностранного государства в части конфискации находящихся на территории Россий- ской Федерации доходов, полученных преступным путем (гл. 55.1 УПК РФ) [12].

Поручения об оказании правовой помощи по материалам проверки, проводимой в порядке ст. ст. 144, 145 УПК РФ, подлежат направлению на основании двусторонних соглашений о сотрудничестве между Российской Федерацией и запрашиваемой стороной.

При взаимодействии по уголовным делам в форме дознания каждой из сторон требуется выполнение тех следственных действий, которые предусмотрены ее законодательством. Обращаться с просьбой о расширении перечня следственных действий не допустимо, поскольку при заключении договора стороны руководствуются действующим законодательством своего государства.

Нарушение условий международных договоров может привести к отказу в исполнении поручений об оказании правовой помощи по уголовным делам.

Изучение уголовных дел, расследованных дознавателями органов внутренних дел, и анализ сведений о направлении поручений об оказании правой помощи, подготовленных дознавателями подразделений дознания территориальных органов МВД России за 2015-2020 годы, показывает, что ежегодно дознавателями направляется в адрес компетентных органов иностранных государств порядка 270 запросов (поручений) об оказании правовой помощи по уголовным делам. Наибольшее их количество направлено дознавателями по уголовным делам, возбужденным по фактам совершения иностранными гражданами преступлений, предусмотренных статьями 112, 119, ч. 1 ст. 158, ч. 1 ст. 159 , ч. 1 ст. 228 , ст. 264.1, ч. 1 ст. 322.1 , ч. ч. 1 и 3 ст. 327 УК РФ. $85 \%$ таких поручений (запросов) направляется в страны СНГ. Вместе с тем при подготовке поручений (запросов) дознавателями допускаются ошибки, которые служат основанием для их возвращения инициатору без исполнения, что способствует необоснованному продлению сроков расследования, негативно сказываются на ходе расследования. Рассмотрим типичные ошибки, допускаемые дознавателями органов внутренних дел при составлении и направлении поручений (запросов) об оказании правовой помощи по уголовным делам, к которым относятся":

${ }^{1}$ По материалам ООД ГУ МВД России по Красноярскому краю: Информационные письма, обзорь УОД МВД России, ООД ГУ МВД России по Красноярскому краю за 2015-2020 г.г. // Наблюдательное дело ООД ГУ МВД России по Красноярскому краю.
107

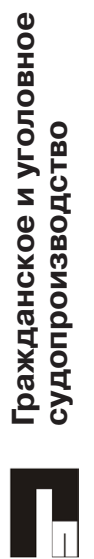


- несоответствие поручения по форме и содержанию, выразившееся в неверном указании официального названия запрашиваемого государства (Кыргызстан вместо Кыргызской Республики, Республика Украина вместо Украина);

- нарушение требований уголовнопроцессуального законодательства Российской Федерации и Минской Конвенции о приобщении к поручению об оказании правовой помощи судебного решение при запросе сведений ограниченного доступа. Дознавателем направлено поручение в Эстонскую Республику с просьбой о производстве выемки сведений о пользователе сети Интернет. При этом в нарушение требований ч. 3 ст. 165, ст. 183 УПК РФ, ст. ст. 53, 63 Федерального закона от 07.07.2003 № 126-ФЗ «О связи» решение суда не приобщено к поручению;

- отсутствие в запросах сведений о статусе лица, подлежащего допросу;

- запрос сведений, характеризующих личности свидетеля и потерпевшего по делу, тогда как такие сведения могут быть запрошены только на подозреваемого;

- отсутствие сведений о гражданстве запрашиваемого лица; неприобщение копии паспорта, выписок статей из УК РФ, УПК РФ. В связи с допущенными нарушениями поручения, направленные компетентным органам Республики Узбекистан и Республики Таджикистан, возращены без исполнения;

- нарушение порядка препровождения поручения об оказания правовой помощи в компетентные органы иностранного государства, минуя МВД России. Так, из аппарата Следственного комитета Республики Беларусь без исполнения возвращен запрос, направленный в нарушение требований статьи 7 Минской Конвенции факсимильной связью. В запросе, представленном в одном экземпляре, отсутствовала ссылка на правовую основу его направления и не был заверен гербовой печатью. Кроме того, инициатор запроса ходатайствовал о проведении следственных действий на территории иностранного государства в отношении лица, являющегося гражданином Республики Беларусь, в качестве подозреваемого с разъяснением ему положений статьи 51 Конституции Российской Федерации.

В уголовно-процессуальном законодательстве Российской Федерации, как и в ряде международных договорах, предусмотрены нормы, допускающие отказ в оказании правовой помощи. Каждая из сторон взаимодействия по уголовным делам выполняет следственные действия, предусмотренные законодательством подписанта. Подобные нормы закреплены и в двусторонних договорах Российской Федерации. Так, в соответствии с пунктом 1 статьи 25 Договора между Российской Федерацией и Китайской Народной Республикой о правовой помощи по гражданским и уголовным делам (подписан в г. Пекине 19.06.1992) в предоставлении правовой помощи Сторона может отказать, если деяние, указанное в поручении, по законодательству запрашиваемой Договаривающейся Стороны не является преступлением. В этой связи запрос отдела дознания МО МВД России «Уярский» Красноярского края о предоставлении сведений о личности гражданина Китайской Народной Республики подозреваемого по уголовному делу в совершении преступления, предусмотренного ч. 1 ст. 322.1 УК РФ (Организация незаконной миграции), адресованный компетентным органам Китайской Народной Республики, был возращен без исполнения. В Китайской Народной Республике за совершение деяния аналогичного характера уголовная ответственность не предусмотрена.

Изучение уголовных дел, расследованных дознавателями УМВД России по Владимирской области, Гу МВД России по г. Санкт-Петербургу и Ленинградской области, гУ МВД России по г. Москве и по Красноярскому краю, УМВД России по Смоленской области, а также обзоров и информационных писем свидетельствует о том, что непринятие должных мер сотрудниками органа дознания в отношении граждан - мигрантов из ближнего зарубежья, прибывших в Россию в целях трудоустройства, приводят к сокрытию лиц, подозреваемых в совершении преступлений. Так, уголовное дело № 548042 в отношении гражданина Республики Таджикистан П. возбуждено по признакам преступления, предусмотренного 4.1 ст.119 УК РФ, спустя месяц с момента совершения преступления. Подозреваемый скрылся до возбуждения уголовного дела, еще при проведении «доследственной» проверки. Уголовное дело впоследствии приостановлено. Аналогичные факты установлены и по другим уголовным делам: № 2041, возбужденному в отношении гражданина Республики Узбекистан А.; № 72107, возбужденному в отношении гражданки Республики Узбекистан М.; № 502541, возбужденному в отношении гражданина Кыргызской Республики ж. и др., информация об отсутствии лиц по месту своего жительства (регистрации) документально не была подтвержде- 
на, международные поручения об оказании правовой помощи с целью установления местонахождения подозреваемых своевременно не направлялись $[14$, с. 212-220].

Между тем по законодательству Республики Узбекистан (ст. 603 УПК), так же, как и Российской Федерации, не допускается выдача иностранному государству лица, являющегося гражданином этой страны и находящегося на территории Узбекистана. Следовательно, в приведенных случаях подлежат применению нормы, регулирующие направление материалов уголовного дела в государство гражданства подозреваемых для уголовного преследования, при наличии достаточных доказательств, подтверждающих их причастность к совершению расследуемого преступления [13].

Проблемой оказания правовой помощи при исполнении запросов (поручений) по уголовным делам является отсутствие в международных договорах и национальном законодательстве норм, устанавливающих сроки исполнения запросов о правовой помощи. Сроки исполнения запросов компетентными органами иностранных государств составляют от двух до десяти месяцев, по некоторым уголов- ным делам достигают двух лет. Обеспечение разумности сроков расследования для российского уголовного судопроизводства является актуальной, поскольку их соблюдение способствует всестороннему и объективному исследованию фактических обстоятельств преступления, изобличению виновных в его совершении лиц и восстановлению нарушенных прав лиц, потерпевших от противозаконных деяний.

Кроме того, следует отметить пробельность норм внутреннего законодательства и международного уровня, регламентирующих решение вопроса о направлении уголовных дел для осуществления уголовного преследования в отношении лиц с несколькими гражданствами, одно из которых является, в том числе и российским. В связи с нормативной неопределенностью такое лицо имеет возможность скрыться в одной из стран своего гражданства, пытаясь избежать уголовной ответственности.

Указанные проблемы свидетельствуют о необходимости изменений норм, регулирующих взаимодействие компетентных органов в сфере международного сотрудничества по оказанию правовой помощи по уголовным делам.

\section{Литература}

1. Европейская конвенция о взаимной правовой помощи по уголовным делам 1959 г. с дополнительными протоколами [Электронный ресурс] // СПС КонсультантПлюс.

2. Европейская конвенция о выдаче от 13.12.1957, с Дополнительными протоколами от 15.10.1975 и от 17.03.1978 [Электронный ресурс] // СПС КонсультантПлюс.

3. Договор между Российской Федерацией и Азербайджанской Республикой о правовой помощи и правовых отношениях по гражданским, семейным и уголовным делам (Москва, 1992) // Собрание законодательства РФ. 1995. № 18. Ст. 1598.

4. Конвенция о правовой помощи и правовых отношениях по гражданским, семейным и уголовным делам (заключена в г. Минске 22.01.1993) (ред. от 28.03.1997) [Электронный ресурс] // СПС КонсультантПлюс.

5. Конституция Российской Федерации. М.: Эксмо, 2020. 64 с.

6. Концепция внешней политики Российской Федерации: Указ Президента Российской Федерации от 30.11.2016 № 640 [Электронный ресурс] // СПС КонсультантПлюс

7. Милинчук В.В. Институт взаимной правовой помощи по уголовным делам: действующая практика и перспективы развития. М., 2001. С. 13-14.

8. Моторин В.В. Международное сотрудничество следователей в сфере оказания правовой помощи по уголовным делам. Домодедово: ВИПК МВД России. 2007. С. 79.

9. О порядке выезда из Российской Федерации и въезда в Российскую Федерацию: Федеральный закон от 15.08.1996 №114-ФЗ [Электронный ресурс] // СПС КонсультантПлюс.

10. Основы уголовного судопроизводства / М.В. Бубчикова, В.А. Давыдов, В.В. Ершов и др.; под ред. В.А. Давыдова, В.В. Ершова. М.: РГУП, 2017. 444 с. 11. Отчет по форме федерального статистического наблюдения 4-ЕГС «Общие сведения о состоянии преступности» за 2016-2020 гг. / Статистические сборники Генеральной прокуратуры Российской Федерации «Состояние преступности в России». М., 2016 2017, 2018, 2019, 2020 [Электронный ресурс] // Доступ из http://crimestat.ru/analytics (дата обращения 08.08.2020 г.).

12. Уголовно-процессуальный кодекс Российской Федерации: Федеральный закон от 18.12.2001 № 174-ФЗ [Электронный ресурс] // СПС КонсультантПлюс.

109

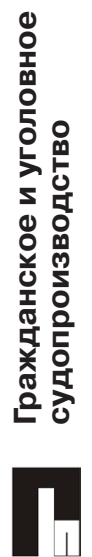


13. Уголовно-процессуальный кодекс Республики Узбекистан (утвержден Законом Республики Узбекистан от 22 сентября 1994 года № 2013-XII) (Электронный ресурс] // https://online.zakon.kz/Document/?doc_id=30421101\&doc_id2=3 $0421101 \#$ pos $=6 ; 98 \&$ pos $2=4878 ;-80$.

14. Якубова С.М. Дифференциация сроков расследования в связи с приостановлением производства по уголовному делу: дис...канд. юрид. наук. М., 2017. C. $212-220$.

\section{References}

1. Evropejskaja konvencija o vzaimnoj pravovoj pomoshhi po ugolovnym delam 1959 g. s dopolnitel'nymi protokolami [Jelektronnyj resurs] // SPS Konsul'tantPljus.

2. Evropejskaja konvencija o vydache ot 13.12.1957, s Dopolnitel'nymi protokolami ot 15.10.1975 i ot 17.03.1978 [Jelektronnyj resurs] // SPS Konsul'tantPljus.

3. Dogovor mezhdu Rossijskoj Federaciej i Azerbajdzhanskoj Respublikoj o pravovoj pomoshhi i pravovyh otnoshenijah po grazhdanskim, semejnym i ugolovnym delam (Moskva, 1992) // Sobranie zakonodatel'stva RF. 1995. № 18. St. 1598.

4. Konvencija o pravovoj pomoshhi i pravovyh otnoshenijah po grazhdanskim, semejnym i ugolovnym delam (zakljuchena v g. Minske 22.01.1993) (red. ot 28.03.1997) (vstupila v silu 19.05.1994, dlja Rossii 10.12.1994) [Jelektronnyj resurs] // SPS Konsul'tantPljus.

5. Konstitucija Rossijskoj Federacii. M.: Jeksmo, 2020. 64 s.

6. Koncepcija vneshnej politiki Rossijskoj Federacii: Ukaz Prezidenta Rossijskoj Federacii ot 30.11.2016 № 640 [Jelektronnyj resurs] // SPS Konsul'tantPljus.

7. Milinchuk V.V. Institut vzaimnoj pravovoj pomoshhi po ugolovnym delam: dejstvujushhaja praktika i perspektivy razvitija. M., 2001. S. 13-14.

8. Motorin V.V. Mezhdunarodnoe sotrudnichestvo sledovatelej v sfere okazanija pravovoj pomoshhi po ugolovnym delam. Domodedovo: VIPK MVD Rossii. 2007. S. 79 .

9. O porjadke vyezda iz Rossijskoj Federacii i v\#ezda v Rossijskuju Federaciju: Federal'nyj zakon ot 15.08.1996 №114-FZ [Jelektronnyj resurs] // SPS Konsul'tantPljus.

10. Osnovy ugolovnogo sudoproizvodstva / M.V. Bubchikova, V.A. Davydov, V.V. Ershov i dr.; pod red. V.A. Davydova, V.V. Ershova. M.: RGUP, 2017. 444 s.

11. Otchet po forme federal'nogo statisticheskogo nabljudenija 4-EGS «Obshhie svedenija o sostojanii prestupnosti» za 2016-2020 gg. / Statisticheskie sborniki General'noj prokuratury Rossijskoj Federacii «Sostojanie prestupnosti v Rossii». M., 2016 2017, 2018, 2019, 2020 [Jelektronnyj resurs] // Dostup iz http://crimestat.ru/ analytics (data obrashhenija 08.08.2020 g.).

12. Ugolovno-processual'nyj kodeks Rossijskoj Federacii: Federal'nyj zakon ot 18.12.2001 № 174-FZ [Jelektronnyj resurs] // SPS Konsul'tantPljus.

13. Ugolovno-processual'nyj kodeks Respubliki Uzbekistan (utverzhden Zakonom Respubliki Uzbekistan ot 22 sentjabrja 1994 goda № 2013-XII) [Jelektronnyj resur s] // https://online.zakon.kz/Document/?doc_id=30421101\&doc_id2=30421101\# pos $=6 ; 98 \&$ pos $2=4878 ;-80$.

14. Jakubova S.M. Differenciacija srokov rassledovanija v svjazi s priostanovleniem proizvodstva po ugolovnomu delu: dis...kand. jurid. nauk. M., 2017. S. 212-220.

ГУМАРОВ Ильнур Асгатович, доцент кафедры оперативно-разыскной деятельности Казанского юридического института МВД России кандидат юридических наук. 420108, Республика Татарстан, г. Казань, ул. Магистральная, 35. E-mail: ilnur_gumar@mail.ru

GUMAROV IInur Asgatovich, Associate Professor of the Department of Operational-Investigative Activities of the Kazan Law Institute of the Ministry of Internal Affairs of Russia, Candidate of Legal Sciences. 420108, Republic of Tatarstan, Kazan, st. Magistralnaya,35. E-mail: ilnur_gumar@mail.ru.

ЯкУБОВА Сельхе Махачевна, старший преподаватель кафедры уголовного процесса Сибирского юридического института МВД России кандидат юридических наук. 660131, Красноярский край, г. Красноярск, ул. Рокоссовского, 20. E-mail: selhe@mail.ru.

YAKUBOVA Selkhe Makhachevna, Senior Lecturer of the Department of Criminal Procedure of the Siberian Law Institute of the Ministry of Internal Affairs of Russia, Candidate of Law. 660131, Krasnoyarsk Territory, Krasnoyarsk, st. Rokossovsky, 20. E-mail: selhe@mail.ru. 